\title{
Proposta para a adequação da tipologia e para a identificação dos componentes biofísicos dos atrativos naturais nos destinos de ecoturismo no Brasil
}

\author{
Proposal for adaptation of the typology and identification of the \\ biophysical components of natural attractions in ecotourism \\ destinations of Brazil
}

\section{Propuesta para la adecuación de la tipología y para la identificación de los componentes biofísicos de los atractivos naturales en los destinos de ecoturismo en Brasil}

\section{Paulo dos Santos Pires ${ }^{1}$}

\begin{abstract}
Resumo: No contexto da relação entre o turismo e as áreas naturais e, mais especificamente, da demanda turística em relação à natureza e aos recursos nela contidos, capazes de despertar o interesse humano pelo contato direto, conhecimento e fruição, o presente artigo aborda a tipologia dos recursos naturais e atrativos associados nos destinos de ecoturismo no Brasil, com ênfase nos seus componentes biofísicos. Para tanto, realizou-se uma abordagem, sobretudo, qualitativa, voltada para uma amostra de operadoras de turismo na natureza e ecoturismo no Brasil. A análise de conteúdo dos dados compilados e sistematizados resultou, primeiramente, na apresentação de um quadro síntese da tipologia dos recursos naturais e das atividades que ocorrem nos 45 destinos do ecoturismo, identificados como os de maior oferta e com representatividade nacional. Em seguida, propõe-se um quadro para a classificação da categoria atrativos naturais, com uma tipologia associada às características relevantes e com aplicação específica para o registro dos atrativos do ecoturismo. Por fim, apresenta-se uma proposta de identificação e descrição dos componentes naturais dos destinos de ecoturismo com base em um modelo de composição visual da paisagem, exemplificada em três destinos preferenciais deste segmento. Os resultados obtidos expressam a possibilidade de se valer do ordenamento e da sistematização de informações sobre os atrativos naturais e atividades relacionadas, para alcançar um melhor padrão de apresentação e descrição da "matéria prima" das agências e operadoras de ecoturismo, assim, melhor atender às necessidades de qualidade e diferenciação requeridas para este segmento. Já para o meio acadêmico, poderá se constituir em uma contribuição metodológica para o ensino e a pesquisa sobre o tema.
\end{abstract}

Palavras chave: Atrativos naturais; Ecoturismo; Paisagem.

\footnotetext{
${ }^{1}$ Engo Florestal pela UFSM-RS e Doutor em Ciências (Geografia Humana) pela USP-SP. Docente e pesquisador da UNIVALI-SC atuando nos Programas de stricto sensu em Turismo e Hotelaria e em Administração e na graduação em Turismo e Hotelaria. pires@univali.br
} 
Abstract: In the context of the relationship between tourism and natural areas, and more specifically, tourism demand in relation to nature and the resources offered by it, capable of attracting human interest in learning more about, having direct contact with, and enjoying nature, this article addresses the typology of the natural resources and associated attractions in the ecotourism destinations of Brazil, with emphasis on their biophysical components. This work uses a mainly qualitative approach, focusing on a sample of tourism operators in the area of nature and ecotourism in Brazil. The content analysis of the compiled, systematized data resulted, primarily, in the presentation of a table summarizing the typology of the natural resources and the activities that take place in forty-five nature and ecotourism destinations, identified as those with the largest offer and with national representativeness. It then proposes a table for the classification of the category natural attractions, with a typology associated with the relevant characteristics that have specific application for registering the tourism attractions in nature. Finally, it presents a proposal for the identification and description of the natural components of ecotourism destinations, based on a model of visual composition of the landscape, which is exemplified in three favourite destinations of this segment. The results obtained express the possibility of making use of the ordering and systematization of information on the natural attractions and related activities, to achieve a better standard of presentation and description of the "raw material" of ecotourism agencies and operators and better meet the needs for quality and differentiation required for this segment. For academics, it can provide a methodological contribution to teaching and research on the subject.

\section{Keywords: Natural Attractions; Ecotourism; Landscape.}

Resumen : En el contexto de la relación entre el turismo y las áreas naturales y, más específicamente, de la demanda turística en relación a la naturaleza y a los recursos contenidos en ella, capaces de despertar el interés humano por contacto directo, conocimiento y fruición, el presente artículo aborda la tipología de los recursos naturales y atractivos asociados en los destinos de ecoturismo en Brasil, con énfasis en sus componentes biofísicos. Para ello, se realizó un abordaje, predominantemente cualitativo, focalizado en una muestra de operadores mayoristas de turismo en la naturaleza y ecoturismo en Brasil. El análisis de contenido de los datos compilados y sistematizados resultó, primeramente, en la presentación de un cuadro síntesis de la tipología de los recursos naturales y de las actividades que ocurren en los 45 destinos de ecoturismo, identificados como los de mayor oferta y con representatividad nacional. En seguida, se propone un cuadro para la clasificación de la categoría atractivos naturales, con una tipología asociada a las características relevantes y con aplicación específica para el registro de los atractivos de ecoturismo. Por fin, se presenta una propuesta de identificación y descripción de los componentes naturales de los destinos de ecoturismo con base en un modelo de composición visual del paisaje, ejemplificada en tres destinos preferenciales de este segmento. Los resultados obtenidos expresan la posibilidad de valerse del ordenamiento y de la sistematización de informaciones sobre los atractivos naturales y actividades relacionadas, para alcanzar un mejor estándar de presentación y descripción de la "materia prima" de las agencias y operadores mayoristas de ecoturismo, para así, atender mejor a las necesidades de calidad y diferenciación requeridas para este segmento. Por otro lado, para el medio académico, podrá constituirse en una contribución metodológica para la enseñanza y la pesquisa sobre el tema.

Palavras chave: Atractivos naturales; Ecoturismo; Paisaje.

\section{INTRODUÇÃO}

O turismo na natureza e no seu bojo o ecoturismo, enquanto paradigma de sustentabilidade, desde meados da década de 1990 tornaram-se pujantes segmentos do turismo tanto em nível mundial como no Brasil, país que com sua notável biodiversidade e profusão de 
ecossistemas, desponta neste cenário com uma amplitude de recursos e paisagens naturais de reconhecido potencial para suprir a crescente demanda turística doméstica e internacional voltada para estes segmentos.

A constatação deste potencial se assenta em uma base ecológica constituída por sete grandes ecossistemas - os Biomas, além das áreas de transição entre eles. Já em escala regional, os Biomas podem ser reconhecidos em 49 Ecorregiões (WWF, 2005), cujo conhecimento se torna muito útil para o planejamento do turismo nesta escala. Por outro lado, percebe-se que em escala mais localizada, ao nível dos destinos, ainda não há uma referência de sistematização das informações sobre os atrativos naturais e suas respectivas paisagens, que seja plenamente aceita e utilizada especialmente na operacionalização do turismo em áreas naturais.

Por sua vez no meio acadêmico e no âmbito da pesquisa aplicada, o referencial utilizado para a sistematização, o ordenamento e a classificação de dados pertinentes aos atrativos em destinos do turismo na natureza, via de regra, tem por base os modelos clássicos de inventário e classificação encontrados, por exemplo, em Cerro (1993), Roa, et al. (1998) e Camprubi et al. (1998), não obstante já estarem disponíveis os manuais e formulários para o inventário da oferta turística do Ministério do Turismo (Brasil, 2001; 2006; 2011).

Porém, a amplitude destes referenciais para todo o espectro turístico não permite focar apenas no interesse específico de determinados segmentos como o ecoturismo, cujo foco na natureza e valores culturais do seu entorno, exigirá por parte dos envolvidos um cuidado e um esforço de adequações e ajustes quando da utilização destes referenciais de inventário e de classificação atualmente disponíveis.

A partir deste entendimento foram delineados os objetivos que nortearam a pesquisa documental e o estudo propositivo materializado no presente artigo, quais sejam: a) apresentar um quadro síntese da tipologia dos recursos naturais e atrativos correspondentes, com maior ocorrência nos 45 destinos brasileiros identificados como os de maior oferta nos segmentos turismo na natureza/ecoturismo; b) expor um modelo de identificação e descrição sintética dos componentes naturais nos destinos de turismo na natureza, com base na composição visual das suas paisagens, exemplificado através de três destinos preferenciais deste segmento no Brasil; e c) apresentar um quadro de referência para o levantamento, classificação e registro de atrativos do turismo na natureza e ecoturismo, com base no marco conceitual da OMT (2001) e no manual do inventário da oferta turística do Ministério do Turismo (Brasil, 2006).

Com isso, os objetivos assim estabelecidos permitirão vislumbrar duas facetas: a primeira de natureza empírica reveladora dos recursos naturais e respectivos atrativos mais recorrentes nos destinos de turismo na natureza no Brasil; e a segunda de caráter metodológico-instrumental, com a proposição dos modelos e quadros de referência para o levantamento e descrição especificamente dos atrativos do turismo na natureza e ecoturismo. 


\section{MARCO CONCEITUAL}

Neste espaço será exposta uma sucinta base conceitual acerca dos termos que se configuram como palavras-chave balizadoras para o desenvolvimento do presente estudo.

\subsection{Do patrimônio ao atrativo turístico}

De acordo com Cerro (1993), as ocorrências, manifestações e atributos da natureza, na sua forma original, se constituem em um patrimônio ou bem - e nesta condição ainda não passam de um conjunto de potencialidades-, os quais o homem poderá transformar em recurso, utilizando os meios técnicos e econômicos próprios do seu contexto cultural, político e social. Dessa forma, de acordo com a mesma fonte, o recurso não se define por sua própria existência e, sim, por sua capacidade para satisfazer uma necessidade humana. É este ato de exploração o que converte um elemento em recurso". (Small e Witherich' citados por Cerro, 1993, p. 29)

Assim, um determinado patrimônio natural (elemento da natureza) se converte em recurso turístico quando, mediante uma intervenção humana, se torna utilizável turisticamente, seja na condição de motivador da demanda turística (Atrativo Turístico Natural), seja na condição de recurso utilizado por esta mesma demanda durante a sua experiência turística e permanência no local ou destino escolhido, a exemplo da água, dos solos e demais ecossistemas naturais com os "serviços ambientais" que deles derivam.

Com isso, "a base de desenvolvimento do turismo repousa sobre a existência de certos elementos e manifestações de origem natural e cultural que despertam o interesse nato do ser humano [...] (Pires, 2008, p. 252), o que conduz à constatação de que a noção de utilização humana está na base da caracterização dos recursos, sejam eles úteis ao turismo ou a qualquer outra atividade humana. (Roa et al., 1987).

Dessa forma, o turismo como atividade econômica utiliza recursos - sua "matéria prima", consumindo-os em seu próprio lugar de origem. A existência destes, portanto, está na origem do fato turístico e, segundo Cerro (1993), trata-se de uma condição prévia para o desencadeamento da demanda, formando uma parte essencial da oferta turística.

Reconhecidas estas características, os recursos turísticos por definição são "todos os bens e serviços que, por intermédio da atividade do homem e dos meios com que conta tornam possível a atividade turística e satisfazem as necessidades da demanda" (OMT, 2001, p. 172). Assim, a atividade turística poderá se desencadear se, entre os referidos bens existirem certos elementos da natureza dotados de determinados atrativos que possam provocar a curiosidade e motivação turística nas pessoas, ou seja, que as faça deslocar de seu domicílio habitual e permanecer determinado tempo em contato com tais elementos para realizar atividades de cunho físico, social, intelectual ou espiritual. Estas adquirem então o status de recursos turísticos (naturais ou culturais) (Cerro, 1993). 
Furio (1996) esclarece que somente uma parcela dos recursos naturais são no sentido estrito fatores de atração turística. A estes se denomina de atrativos turísticos naturais ou atrativos naturais do turismo. Já o restante dos elementos da natureza necessários para o desenvolvimento turístico na sua condição de geradores de insumos e de fornecedores de serviços ambientais, mas que não são fatores de atração, simplesmente, são denominados de recursos naturais. $\mathrm{O}$ autor (op cit) esclarece ainda que um mesmo recurso físico pode ser simultaneamente um atrativo turístico natural e um recurso natural do turismo.

Pode-se então assumir as seguintes definições para recursos naturais: "aquelas riquezas que se encontram em estado natural para ser utilizadas racionalmente em benefício da humanidade" ou, ainda, "tudo quanto existe na natureza, atual ou potencialmente utilizável pelo homem". (Roa et al, 1987, p. 11; 12, citando, respectivamente, Solórzano" e Beltrán iii). Quanto aos atrativos naturais recebem a seguinte definição operacional do Ministério do Turismo (Brasil, 2006, p. 14): "são elementos da natureza que, ao serem utilizados para fins turísticos, passam a atrair fluxos turísticos (montanhas, rios, cavernas, cachoeiras, clima, flora, fauna)".

\subsection{Classificação e caracterização dos atrativos naturais}

Para Carelless (1992) a classificação de distintos recursos naturais do turismo é um prérequisito essencial do inventário, o que irá permitir uma avaliação padronizada em tipos de produtos e respectivos atributos. Tal classificação fornece uma estrutura a partir da qual a metodologia de inventário e análise é construída.

É pertinente que os elementos que integram a natureza possam ser agrupados ou individualizados quando representam importantes recursos naturais, facilitando a sua localização, estabelecimento de inter-relações, aproveitamento, etc. (Roa et al., 1987). Também, de acordo com Smith (1992) a localização e o inventário dos recursos, juntamente com a localização de instalações e atividades, é um aspecto importante na descrição de um destino turístico ou de recreação.

Sendo assim, os métodos mais avançados para o inventário de recursos incluem as classificações designadas pelo autor (op cit) de "aglomerativas", que consistem em agrupar os recursos identificados em categorias mais gerais, e as "desglomerativas" que, ao contrário, consistem em dividir uma região ou um grupo de recursos em subgrupos específicos. Por outro lado, segundo a mesma fonte, "o inventário de recursos pode ser realizado por meio da simples enumeração destes ou mediante a criação de modelos de sistemas mais ou menos complexos que combinem de forma aritmética as variáveis descritivas", variáveis estas que representam as características biofísicas intrínsecas e específicas de cada recurso (p.26).

O inventário e o registro de recursos para o turismo constitui uma etapa do que Murta e Goodey (2002) denominam de plano interpretativo, no âmbito da estratégia de interpretação do patrimônio (natural e cultural) para visitantes em destinos turísticos. Como primeiro passo para a análise do potencial turístico, o inventário facilita a identificação dos elementos ou atividades que 
tem um certo poder atual ou potencial para atrair a demanda turística. (Cerro, 1993). Apenas para que se tenha uma noção, o universo classificatório dos recursos do turismo pode ser visualizado da seguinte forma: a) classificações baseadas na tipologia dos recursos; b) classificações baseadas na tipologia e importância dos recursos; c) Classificação dos recursos naturais segundo a intensidade de uso; d) classificação dos recursos naturais segundo suas características principais e secundárias; e d) sistema de classificação dos recursos naturais para inventário nacional. (idem).

\subsection{A dimensão visual da paisagem para o turismo}

Ao deslocar-se desde sua origem até um determinado destino o turista encontra na paisagem o fator que melhor Ihe indicará o rompimento com a rotina, através da percepção visual do novo e do diferente no curso de sua experiência de viagem (Font, 1989). Esta constatação pode ser respaldada no entendimento de que em sua dimensão visual/estética, a paisagem é o domínio do visível ou de tudo aquilo que a visão abarca (Santos, 1988) ou, ainda, a expressão espacial e visual do ambiente [...] porção do espaço observado pela visão humana (Bombin, et al., 1987).

Nesta condição, a paisagem gera um estímulo que para Laurie (1970) é definido por suas formas topográficas e seus elementos de superfície. Depreende-se daí que tais formas e elementos compõem a paisagem que se apresenta diante do campo de percepção visual do observador. Portanto, a composição visual de uma paisagem, seja ela natural ou humanizada, é derivada basicamente das suas formas de relevo, aqui assumidas em sua equivalência às "formas topográficas" de Laurie (op cit.), e dos seus elementos de superfície.

As formas de relevo, não obstante estarem associadas aos grandes conjuntos de paisagens de relevo como os planaltos, planícies, serras e depressões (Guerra, 1993), em uma escala mais localizada correspondente ao campo de alcance visual de um observador posicionado na superfície terrestre, relacionam-se às formas planas, salientes ou deprimidas do terreno, ou às suas feições morfológicas, dando origem a um conjunto bastante variado de ocorrências do relevo, como os afloramentos, canyons, colinas e morros, entre outras.

Já os elementos de superfície estão relacionados às ocorrências naturais ou às atividades humanas que tem a superfície terrestre como substrato biológico, suporte físico ou fator delineador e condicionante de sua existência ou ocorrência. Referem-se, portanto, à hidrografia (rios, lagos, quedas d'água), à vegetação natural em suas distintas formações e estruturas, à fauna (terrestre, aérea e aquática) e ao uso do solo por atividades humanas, sejam elas no meio natural, rural ou urbano. Dessa forma, as formas de relevo e os elementos de superfície ao definirem uma determinada composição visual, passam a se constituir no que Laurie (1970) denominou de estímulo ambiental de uma paisagem diante do observador.

Assim, a composição visual supõe a existência de uma base física estabelecida em duas escalas espaciais: uma escala regional onde uma determinada unidade de relevo revela a característica topográfica dominante; e uma escala localizada, porém inserida neste contexto dominante, revelando as formas planas, côncavas e convexas do relevo, sobre as quais estão 
assentados ou são moldados os demais componentes biofísicos da paisagem, materializados na hidrografia, na cobertura vegetal e na presença e mobilidade tanto da fauna quanto dos seres humanos.

Circunstancialmente as influências climáticas e/ou atmosféricas tais como pluviosidade, insolação, nebulosidade e neve, entre outras possíveis, poderão ser consideradas como fatores de modificação da composição visual básica da paisagem (Pires, 2003), isto porque as condições atmosféricas e meteorológicas modificam as propriedades visuais dos elementos em uma paisagem, seu grau de visibilidade e a nitidez da visão. Consequentemente, de acordo com Bombin et al. (1987), em função de determinada posição de insolação, uma superfície perde a definição de sua textura e o contraste de suas cores, ao passo que suas formas podem se salientar, assim como diante da falta da ausência da mesma (dias nublados) as cores se tornam opacas.

Contudo, para se tornar realmente um recurso visual, a paisagem dependerá, em parte, da sua qualidade estética ou cênica, sendo que esta, de acordo com Litton (1972) é um atributo que deriva do valor dado a uma paisagem em decorrência de seus estímulos visuais. Pode ser entendida também como o grau de excelência de suas características visuais constituindo-se no mérito para que esta mesma paisagem não seja alterada ou destruída (Ministério de Medio Ambiente, 2004).

Portanto, a paisagem se constitui em uma privilegiada categoria de análise para o reconhecimento da vocação e potencialidade turística de um determinado lugar. Tal reconhecimento, se tomado sob a perspectiva do planejamento turístico, contempla a análise do potencial turístico de uma área ou região, onde a primeira etapa é, justamente, o inventário dos recursos ali existentes (Pires, 2011). Como tal, a paisagem em sua dimensão visual ou estética deve tomar parte deste processo.

\subsection{O ecoturismo no contexto do turismo na natureza}

Conceitualmente o ecoturismo se insere como uma versão sustentável do turismo voltado para a natureza (PNUMA, 2001; Pires, 2005), e atualmente está posicionado como um segmento prioritário para o desenvolvimento do turismo no Brasil (Brasil, 2006) ao nível de outros dez segmentos, entre eles o Turismo de Aventura, o Turismo Rural, o Turismo de Pesca e o Turismo Náutico.

Segundo Pires (2005) no ecoturismo a principal motivação é a contemplação e a observação das características naturais e dos recursos culturais a ela relacionados nos seus destinos. A idealização de sustentabilidade atribuída universalmente ao ecoturismo, é dada pela incorporação de determinados princípios e características que servem de marco orientador para a sua implantação e desenvolvimento, por parte de todo os setores sociais (públicos e privados) com interesse ou com atuação na área.

Assim, a partir da sua matriz originadora que é o turismo na natureza - a natureza referida obviamente a ambientes naturais, com elevada integridade de suas características originais, e com 
alterações antrópicas não significativas, o ecoturismo busca a sua identidade de acordo com as seguintes orientações: minimização dos impactos ecológicos e culturais negativos nos destinos; adoção da educação ambiental com ênfase na conservação da natureza e nos valores culturais; contribuição para a conservação da biodiversidade; geração de benefícios socioeconômicos para as localidades, regiões e países anfitriões e seus habitantes (Pires, 2005).

\section{METODOLOGIA}

Realizou-se uma abordagem, sobretudo, qualitativa em nível exploratório utilizando-se dados secundários que foram coletados junto a diversas fontes de informação disponíveis. Os procedimentos metodológicos para cada etapa dos resultados obtidos foram os seguintes:

Para a apresentação da tipologia dos atrativos naturais nos destinos de turismo na natureza no Brasil, adotou-se uma amostra por critério intencional de 56 operadoras atuantes e representativas do segmento do turismo na natureza e do ecoturismo, com sede na Grande São Paulo, Brasília e capitais dos Estados do Rio Grande do Sul, Paraná, Minas Gerais, Rio de Janeiro e Bahia. Os dados correspondentes foram então obtidos diretamente a partir das seguintes fontes: Cia Ecoturismo; Free Way Brasil; Ambiental Expedições; Pisa Trekking; Trilhas e Trilhas; Bureau Brasil de Expedições; Adventure Club; Terra Mater; Revista Horizonte Geográfico; Revista Terra; Viagem e Turismo; Quatro Rodas; Ibama; e sites oficiais dos destinos.

O tratamento dos dados, ou seja, dos atrativos do turismo na natureza e ecoturismo operacionalizados por estas empresas, implicou na sua classificação ao nível de um reconhecimento básico e preliminar, considerando apenas a sua tipologia. Cerro (1993) situa essa etapa como um simples inventário que busca agrupar os recursos de forma mais ou menos ordenada e lógica, considerando a sua natureza ou funcionalidade.

Neste sentido, a classificação resultante dos tipos e subtipos de áreas naturais onde se localizam os atrativos do turismo da natureza com maior ocorrência no Brasil em 45 destinos identificados foi elaborada a partir do modelo indicado pela Organização Mundial do Turismo (OMT, 2001) e adotado pelo Ministério do Turismo (Brasil, 2006).

Já a proposta de classificação da categoria atrativos turísticos naturais em tipos e respectivas características e condições relevantes, a serem consideradas para um registro básico dos atrativos do turismo na natureza e ecoturismo, foi desenhada neste estudo tendo como fonte original o modelo da O.E.A (s.d.) encontrado em Cerro (1993), acrescido de contribuições obtidas em Silbermann (1970); Bagnoli (1989) e Najdzion (2002) e de uma referência mais atual que é o Manual do Pesquisador/Formulários do Ministério do Turismo (Brasil, 2006).

A estrutura classificatória está constituída de nove tipologias de atrativos do turismo de natureza/ecoturismo, a saber: Relevo; Hidrografia; Biodiversidade; Zona Costeira; Cavidades Subterrâneas; Singularidades (biogeográficas e atmosféricas); sítios paleoarqueológicos; áreas protegidas; e percursos. Estas tipologias, por sua vez, podem se desmembrar em subtipos, cada 
qual com a identificação de suas características e/ou condições relevantes para o interesse turístico, como será constatado nos resultados.

Por sua vez, o modelo de identificação e descrição sintética dos componentes naturais nos destinos de turismo na natureza, com base na composição visual de suas paisagens, implicou em uma revisão e atualização do modelo proposto por Pires (2003) com a inclusão da característica singular da paisagem como um quarto Fator de Composição que considera a eventual ocorrência de destaques notáveis com potencial de diferenciação, em relação a qualquer um dos componentes biofísicos relacionados às formas topográficas, aos elementos de superfície e às influências atmosféricas. $O$ modelo está representado no quadro 1 a seguir.

Quadro 1 - Caracterização da paisagem através dos fatores de composição e dos seus componentes biofísicos.

\begin{tabular}{|c|l|}
\hline $\begin{array}{c}\text { FATORES DE } \\
\text { COMPOSIÇÃo }\end{array}$ & \multicolumn{1}{|c|}{ COMPONENTES BIOFÍSICOS } \\
\hline $\begin{array}{c}\text { Formas de relevo } \\
\text { (topográficas) }\end{array}$ & - Unidades e formas de Relevo (Geomorfologia) e Declividades \\
\hline $\begin{array}{c}\text { Elementos da } \\
\text { superfície }\end{array}$ & $\begin{array}{l}\text { - Hidrografia } \\
\text { - Vegetação Natural (Biomas) } \\
\text { - Fauna }\end{array}$ \\
\hline $\begin{array}{c}\text { Fatores de } \\
\text { modificação }\end{array}$ & $\begin{array}{l}\text { - Influências climáticas e atmosféricas (temperatura, pluviosidade, insolação, neve, } \\
\text { geleira, umidade) }\end{array}$ \\
\hline $\begin{array}{c}\text { Característica } \\
\text { singular da paisagem }\end{array}$ & $\begin{array}{l}\text { - Anteriormente identificados; } \\
\text { - Atividades humanas em nível de uso do solo, assentamentos com significância } \\
\text { cultural, assim como registros históricos e pré-históricos incorporados à dimensão } \\
\text { visual da paisagem. }\end{array}$ \\
\hline
\end{tabular}

Fonte: Elaboração própria com base em Pires (2001; 2003; 2005).

\section{RESULTADOS}

\subsection{Tipologia dos atrativos naturais nos destinos de ecoturismo no Brasil}

A classificação dos atrativos turísticos naturais e culturais que ocorrem nos destinos de turismo no Brasil, em última instância, se baseia em um modelo gerado pela Organização dos Estados Americanos (OEA, sd) citado por Cerro (1993), concebido para ser aplicado no planejamento turístico em regiões ibero-americanas. Este modelo foi recomendado pela OMT (2001) e no Brasil serve de referência, com adaptações mais ou menos criteriosas, para o inventário turístico em instituições de ensino e, também, para o Ministério do Turismo (Brasil, 2006) em seus instrumentos de orientação para o inventário da oferta turística no Brasil. O quadro 2 a seguir apresenta a relação dos atrativos naturais com maior recorrência em 45 destinos de turismo na natureza e ecoturismo no Brasil, a partir de sua identificação junto a oferta de agências-operadoras atuantes no país, bem como a outras fontes de divulgação, conforme descrito na metodologia. A classificação em tipos e respectivos sub-tipos está de acordo com o modelo acima referido. 
Quadro 2 - Tipos e subtipos de áreas naturais onde se localizam os atrativos do turismo da natureza, além de atividades, com maior ocorrência no Brasil em 45 destinos identificados.

\begin{tabular}{|c|c|}
\hline TIPO (áreas naturais) & SUB-TIPOS (atrativos naturais) \\
\hline MONTANHAS & $\begin{array}{l}\text { Serras, Platôs, Vales, Escarpas, Morros, Planície Elevada, } \\
\text { Planície de Montanha, Cordilheira, Altas Montanhas, } \\
\text { Afloramentos Rochosos, Cânions, Escarpas, Penhascos, } \\
\text { Abismos. }\end{array}$ \\
\hline PLANÍCIES E PLANALTOS & $\begin{array}{l}\text { Terreno Plano, Várzeas, Planícies Sedimentares, Planalto, } \\
\text { Chapadas, Patamares. }\end{array}$ \\
\hline COSTA OU LITORAL & $\begin{array}{l}\text { Recifes, Mangues, Manguezais, Dunas, Praias, Costões, } \\
\text { Ilhas Flúvio-Marinhas, Enseadas, Baias, Restingas, } \\
\text { Falésias }\end{array}$ \\
\hline TERRAS INSULARES & Ilhas, Recifes \\
\hline HIDROGRAFIA & Rios e Nascentes, Praias e Ilhas Fluviais, Lagos, Lagoas \\
\hline QUEDAS D' ÁGUA & Cachoeiras, Cascatas, Cataratas \\
\hline GRUTAS E CAVERNAS & Grutas e cavernas, conforme a denominação local \\
\hline UNIDADE DE CONSERVAÇÃO & $\begin{array}{l}\text { Reserva Ecológica, Parque Nacional e Estadual, RPPN, } \\
\text { APA, FLONA, RDS, Reserva Natural. }\end{array}$ \\
\hline ÁREAS DE CAÇA E PESCA & Pesca de lambaris e de piranhas, \\
\hline CAMINHOS PITORESCOS & $\begin{array}{l}\text { Trilha de acesso, trilha, caminhadas, trekking, passeios } \\
\text { (inclui os embarcados), expedição, trilha off road. }\end{array}$ \\
\hline OBSERVAÇÃO DAFAUNA E FLORA & $\begin{array}{l}\text { Santuários da vida silvestre, focagem noturna (jacarés), } \\
\text { safári fotográfico, observação de pássaros e de aves, } \\
\text { mergulho de observação de tartarugas marinhas, } \\
\text { avistagem de baleias, golfinhos e botos, mergulho de } \\
\text { contemplação de recifes, fazendas, observação da onça } \\
\text { pintada e outros animais terrestres, observação da mata } \\
\text { atlântica, bosques de araucárias, e formações de } \\
\text { veredas. }\end{array}$ \\
\hline \multicolumn{2}{|c|}{ ATRATIVOS TURÍSTICOS CULTURAIS } \\
\hline RUÍNAS E LUGARES ARQUEOLÓGICOS & $\begin{array}{l}\text { Inscrições rupestres } \\
\text { Fragmentos de cerâmica }\end{array}$ \\
\hline
\end{tabular}

Fonte: Welter e Pires (2007), com base em materiais informativos de agências e operadoras de turismo na natureza no Brasil, 2007, revistas especializadas (Horizonte Geográfico, Viagem e Turismo, Terra, Quatro Rodas) e sítios oficiais dos destinos.

O que se denota claramente a partir do resultado obtido é, primeiramente, uma grande variedade de atrativos naturais no território brasileiro quando identificados ao nível de sub tipos, no também diversificado espectro de tipologias básicas de áreas naturais. Ao mesmo tempo, também é possível constatar que predomina o caráter generalista das informações, assim identificadas ao nível de subtipologias de atrativos naturais. Observa-se que ao se utilizar este modelo de classificação aparecem informações que não são propriamente áreas naturais, como "caminhos pitorescos" e "observação da fauna e flora", embora as áreas naturais sejam uma condição necessária para a sua existência.

No espectro de atrativos do turismo na natureza e ecoturismo oferecido pelo trade, há também ocorrências de caráter cultural e histórico que frequentemente ocorrem no entorno dos ambientes naturais, mas que não são contempladas enquanto tipologia no referido modelo. Por 
isso, optou-se por anexar arbitrariamente ao final do quadro a tipologia "ruínas e lugares arqueológicos" na sua correta categoria de "Atrativos Turísticos Culturais".

Ainda, no âmbito da oferta pelo trade verifica-se, por vezes, incongruências técnicas e conceituais quando da designação de determinadas ocorrências naturais. É o caso de "cordilheira", que embora se enquadre no modelo classificatório como subtipo de "montanhas", efetivamente no território brasileiro não ocorrem grandes cadeias de montanhas que se equivalham às cordilheiras dos Andes, Alpes ou Himalaia.

A generalidade desta identificação, em um primeiro momento pode atender ao propósito de uma primeira aproximação em relação ao objeto de interesse, ou seja, ao intento de realizar um inventário geral e inicial dos recursos turísticos de um destino ou região turística, com o mínimo indispensável de organização e de sistematização das informações levantadas. Dessa forma, integrarão uma base de dados a ser posteriormente utilizada em etapas subseqüentes do processo de planejamento e organização do turismo, na realização de pesquisas de caráter acadêmico-científico ou na prospecção e formação do produto (eco) turístico pelo trade.

Tais etapas, que incluem o diagnóstico e avaliação dos destinos e atrativos, prescindirão de um maior apuramento e detalhamento das informações primárias levantadas a campo e, por essa razão, irão requerer outras metodologias e instrumentos específicos e adequados para a sua obtenção, tratamento e análise, cuja abordagem escapa ao foco do presente estudo.

\section{2 Proposta de classificação da categoria atrativos turísticos naturais em tipos e respectivas características e condições relevantes}

O universo de ocorrências e de manifestações da natureza que em sua condição de patrimônio natural são destacados pela atividade turística para se tornarem atrativos, bem como aquelas ocorrências de caráter histórico-cultural a elas associadas, precisa ser não apenas identificado como também organizado de uma forma a permitir um conhecimento mais apropriado, tanto da sua abrangência quanto de sua característica diferenciadora dentro deste universo.

Para tanto, é possível utilizar vários modelos classificatórios e tipológicos que servem de referência de forma genérica para o turismo como um todo e, como tal, não enfocam necessariamente o âmbito específico de determinados segmentos de atuação desta atividade. A partir desta constatação e considerando o segmento específico do ecoturismo, é que se buscou desenhar um modelo voltado para as áreas naturais e seu universo de recursos e atrativos. Não raro, o interesse da demanda ecoturístico se estende a outros recursos de caráter históricocultural que integram o entorno dos atrativos naturais efetivamente tais como os sítios paleoarqueológicos, as terras indígenas, redutos étnicos e assentamentos humanos tradicionais como os de caiçaras no litoral e ribeirinhos no interior do país.

A elaboração inicial deste modelo está representada no Quadro 3 de forma parcial, ou seja, com o estabelecimento de apenas sete tipologias básicas e identificação das subtipologias 
principais. Este modelo classificatório considera o marco conceitual da OMT (2001) e toma como referência o próprio arcabouço tipológico do Inventário da Oferta Turística - Manual do Pesquisador do Ministério do Turismo (Brasil, 2006), incorporando ainda subsídios retirados de outras fontes das áreas específicas relacionadas a certas subtipologias.

Quadro 3 - Tipologias básicas de atrativos naturais do ecoturismo

\begin{tabular}{|c|l|}
\hline \multicolumn{1}{|c|}{ TIPO } & \multicolumn{1}{c|}{ SUBTIPO } \\
\hline RELEVO & $\begin{array}{l}\text { Unidades de Relevo } \\
\text { Formas de Relevo }\end{array}$ \\
\hline HIDROGRAFIA & $\begin{array}{l}\text { Rios de Nascentes } \\
\text { Lagos e Lagoas } \\
\text { Saltos }\end{array}$ \\
\hline ZONA COSTEIRA & Baias, Lagunas, Restingas, Praias, Recifes, Ilhas, ... \\
\hline BIODIVERSIDADE & $\begin{array}{l}\text { Vegetação / Flora } \\
\text { Fauna }\end{array}$ \\
\hline SINGULARIDADES BIOGEOGRÁFICAS & Geográficas, Geomorfológicas, Biológicas, Atmosféricas \\
\hline CAVIDADES SUBTERRÂNEAS & Gruta, Caverna, Grota \\
\hline UNIDADES DE CONSERVAÇÃO & Categorias de UCs. \\
\hline
\end{tabular}

Fonte: Elaboração própria com base em OMT (2001) e Brasil (2006).

A seguir, no quadro 4 apresenta-se o modelo completo com o detalhamento das subtipologias e identificação de suas respectivas características ou condições pertinentes ao aproveitamento turístico.

Quadro 4 - Classificação da categoria atrativos turísticos naturais em tipos e respectivas características e condições relevantes

\begin{tabular}{|c|c|c|}
\hline TIPO & SUBTIPO & CARACTERÍSTICAS / CONDIÇÕES RELEVANTES \\
\hline & $\begin{array}{c}\text { - Unidades de relevo em escala } \\
\text { regional (planícies, planaltos, serras, } \\
\text { chapadas, patamares, tabuleiros, } \\
\text { depressões) } \\
\text { - Formas de relevo em escala } \\
\text { localizada (montanha, encosta, } \\
\text { abismo, afloramento, pico, cânion, } \\
\text { colina, várzea, falésia, morro, monte, } \\
\text { serra, vale, dolina, ...) }\end{array}$ & $\begin{array}{l}\text { Dimensões (alturas, formas; volumes); declividades } \\
\text { predominantes, ocorrências hidrográficas. }\end{array}$ \\
\hline \multirow[t]{3}{*}{ 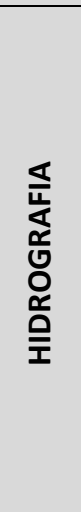 } & Rios e nascentes & $\begin{array}{l}\text { Dimensões (comprimento, largura); forma, profundidade, } \\
\text { caudal e correntezas; sazonalidade hídrica; temperatura; } \\
\text { navegabilidade; balneabilidade; tipo de margens } \\
\text { (arenosas, pantanosas, rochosas); topografia das margens } \\
\text { (plana, declivosa, fechada); desnivelamentos do leito; } \\
\text { presença de fauna aquática e com hábitos aquáticos; } \\
\text { piscosidade; tipo de vegetação ciliar; paisagem do } \\
\text { entorno; existência de atracadouros e pontes. }\end{array}$ \\
\hline & Lagos e lagoas & $\begin{array}{l}\text { Tamanho; profundidade; coloração; temperatura; limpeza; } \\
\text { tipo de margens (arenosas, pantanosas, rochosas) }\end{array}$ \\
\hline & $\begin{array}{c}\text { Saltos } \\
\text { (corredeiras, cascatas, cachoeiras) }\end{array}$ & $\begin{array}{l}\text { Altura; caudal; perfil topográfico da queda; característica } \\
\text { do relevo e da vegetação do entorno; }\end{array}$ \\
\hline
\end{tabular}


Quadro 4 - Classificação da categoria atrativos turísticos naturais em tipos e respectivas características e condições relevantes

\begin{tabular}{|c|c|c|}
\hline TIPO & SUBTIPO & CARACTERÍSTICAS / CONDIÇÕES RELEVANTES \\
\hline ¿ & $\begin{array}{l}\text { Baias, Estuários, Manguezais, } \\
\text { Lagunas, Restingas, Praias, Dunas, } \\
\text { Costões, Falésias, Recifes, Ilha, } \\
\text { Arquipélago, Barra, Península, } \\
\text { Ponta, ... }\end{array}$ & $\begin{array}{l}\text { Clima e estacionalidade; profundidade e balneabilidade } \\
\text { do mar; temperatura, cor/tonalidade e transparência da } \\
\text { água; dimensões (superfície, comprimento, largura); } \\
\text { textura e cor da areia; presença de fauna; tipo de } \\
\text { desembocadura dos rios; integridade dos ecossistemas. }\end{array}$ \\
\hline \multirow[b]{2}{*}{$\begin{array}{l}\text { 岁 } \\
\frac{\mathrm{Q}}{\mathrm{n}} \\
\text { 品 } \\
\text { 음 }\end{array}$} & Vegetação / Flora & $\begin{array}{l}\text { Formação vegetal; porte da vegetação; espécies } \\
\text { características e notáveis. }\end{array}$ \\
\hline & Fauna & $\begin{array}{l}\text { Espécies características e notáveis ao nível de grandes } \\
\text { grupos (aves, répteis, mamíferos, insetos, peixes); hábitos } \\
\text { de reprodução, alimentação, acasalamento, } \\
\text { proteção/abrigo; mobilidade; proeminência na paisagem; } \\
\text { integridade ecológica dos seus habitats ou ambientes } \\
\text { naturais. }\end{array}$ \\
\hline 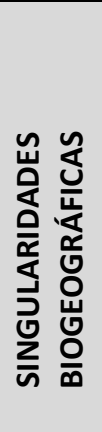 & $\begin{array}{l}\text { Geográficas } \\
\text { Geomorfológicas } \\
\text { Biológicas } \\
\text { Atmosféricas }\end{array}$ & $\begin{array}{l}\text { Determinadas características especiais, notáveis ou } \\
\text { pitorescas tais como: limites de latitude, longitude ou } \\
\text { altitude; pontos continentais extremos; barreiras ou } \\
\text { corredores naturais como patamares de serras; lugares de } \\
\text { nidificação ou passagem de aves migratórias; lugares de } \\
\text { refúgio da fauna e fora; elevada biodiversidade; } \\
\text { ocorrência de refúgios, endemismos e de espécies raras e } \\
\text { em extinção; árvores notáveis pelo seu porte, idade ou } \\
\text { raridade; ocorrências geomorfológicas notáveis; } \\
\text { ocorrências atmosféricas de grande efeito estético. }\end{array}$ \\
\hline 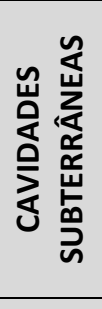 & $\begin{array}{l}\text { - Grutas (secas) } \\
\text { - Cavernas (com água) } \\
\text { - Grota / Lapa }\end{array}$ & $\begin{array}{l}\text { Formação geológica e geomorfológica; cobertura vegetal } \\
\text { do entorno; estética e dimensões da entrada; estética e } \\
\text { dimensões dos espaços internos (galerias, salões, fendas, } \\
\text { desníveis, abismos, reentrâncias. ...); presença de } \\
\text { ornamentos/espeleotemas, de fauna e flora, de pinturas } \\
\text { rupestres, de cursos e espelhos d'água, ou fósseis e } \\
\text { vestígios arqueológicos; associações culturais e históricas }\end{array}$ \\
\hline 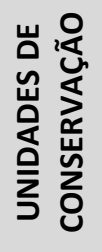 & $\begin{array}{c}\text { Categorias De UCs } \\
\text { (Parques, APAs, RPPNs, ...) }\end{array}$ & $\begin{array}{l}\text { Permissão legal de visitação; existência de zoneamento; } \\
\text { programa de uso público; atrativos naturais específicos; } \\
\text { meios para interpretação da natureza e centro de } \\
\text { visitantes. }\end{array}$ \\
\hline
\end{tabular}

Fonte: Elaboração própria a partir de: Ministério do Turismo (Brasil, 2006); O.E.A (s.d.) in Cerro (1993); e subsídios de Bermann (1970); Bagnoli (1989); Najdzion (2002); IBGE (1993;1995).

Para compor o modelo apresentado no quadro 4 manteve-se a identidade e estrutura geral do modelo do Ministério do Turismo, porém incorporando ou reformulando determinados tipos e subtipos de atrativos, buscando atender justamente ao universo do turismo de natureza e de ecoturismo.

Um aspecto relevante consiste na proposta de adequação para alguns tipos de atrativos constantes da primeira coluna. Assim, introduziu-se a denominação relevo em substituição a 
montanhas, planaltos e planícies, que a exemplo de outras feições e unidades topográficas, passam a ser identificadas coerentemente como unidades ou como formas de relevo e hierarquizadas como subtipo. Já o litoral e as terras insulares mantidos como tipos distintos no atual modelo, foram agrupados na presente proposta sob a denominação zona costeira, uma vez que, por definição (MMA, 2010), estas incluem tanto a porção terrestre que contém os ambientes naturais costeiros, quanto a faixa marítima litorânea que abriga terras insulares como ilhas e recifes de coral.

Na zona costeira, além das formas de relevo e outros aspectos biofísicos naturais, há que se considerar para um registro à parte, a ocorrência de elementos antrópicos histórica e culturalmente relacionados, como edificações e instalações remanescentes do início da povoação, atracadouros e movimento de embarcações tradicionais. Em muitos lugares ao longo da faixa litorânea estes elementos compõem e definem a paisagem em sua unidade, diversidade e singularidade.

Por sua vez a fauna e a vegetação/flora que figuram separadamente como tipos, na condição de elementos vivos do ambiente natural, foram aglutinadas sob a designação biodiversidade, passando então a ser consideradas individualmente ao nível de "subtipos".

Singularidades biogeográficas é uma nova tipologia proposta para abrigar determinadas características especiais, elementos notáveis e ocorrências únicas, que se destacam para além de uma simples ocorrência natural. Tais singularidades podem ser de natureza geográfica, geomorfológica, biológica ou atmosférica, conforme as características respectivas relacionadas no quadro.

Com o mesmo caráter aglutinador das designações relevo, zona costeira e biodiversidade, a designação da tipologia cavidades subterrâneas, passa a representar as ocorrências gruta, caverna, grota e lapa que assim passam para a condição de subtipos.

Por sua vez, as unidades de conservação foram mantidas enquanto designação de tipologia, porém identificando como subtipos as respectivas categorias de UCs definidas pelo Sistema Nacional de Unidades de Conservação.

Quanto às áreas de caça e pesca, não foram consideradas no modelo proposto, primeiramente por se tratar de atividades recreativas ou turísticas e não propriamente atrativos. Além, no caso a pesca, enquanto atividade recreativa, já define por si só um segmento específico do turismo que é o Turismo de Pesca (Brasil, 2006). Quanto à caça, excluindo a caça furtiva e predatória, poderá ser considerada no âmbito de uma das categorias de Unidades de Conservação do SNUC que é a Reserva de Fauna, a qual está voltada para o manejo econômico sustentável dos recursos faunísticos (Brasil, 2004) e, como tal, poderá contemplar atividades turísticas de caça, de acordo com normas estabelecidas em plano de manejo.

$\mathrm{Na}$ última coluna, optou-se por indicar primordialmente as características e condições relevantes relacionadas, sobretudo, aos aspectos inerentes à identidade e atratividade dos recursos naturais relacionados. Neste sentido, não foram incluídos outros aspectos relacionados à infraestrutura e serviços, já que o propósito é o de investir no reconhecimento dos aspectos 
inerentes aos atrativos durante a etapa do levantamento e do registro a serem realizados pelas equipes de campo.

Por fim, o subtipo "Fontes Hidrominerais e/ou termais" não foi considerado por se tratar de um atrativo predominantemente voltado para um outro segmento do turismo que é o Turismo de Saúde e de Lazer (Brasil, 2004), não obstante a demanda pelo turismo de natureza eventualmente inserir em seu roteiro ou programa de viagem este atrativo.

Já a nova versão de formulário de inventário turístico publicada pelo Ministério do Turismo (Brasil, 2011), percebe-se que algumas mudanças tipológicas em relação ao modelo anterior de 2006, que o aproximam mais do modelo aqui proposto, por exemplo, ao adotar a designação das tipologias "Relevo" e "Zona Costeira". Não obstante, ao nível de subtipologia verificam-se diferenças na forma de discriminar ou detalhar os tipos de atrativos.

Assim, enquanto o modelo do MTur não faz diferença entre unidades e formas de relevo, a presente proposta distribui os subtipos em cada uma destas duas dimensões. Curiosamente os elementos bióticos do ambiente natural que são a fauna e a vegetação não constam como tipologia na categoria de atrativo natural do formulário MTur de 2011!!

Há também uma diferenciação na designação de "relevo cárstico" como nova tipologia em substituição a cavernas, grutas e furnas. No entanto, na proposta decidiu-se adotar a designação de "cavidades subterrâneas" para o conjunto destas ocorrências, deixando para enquadrar toda e qualquer outra ocorrência e feição geomorfológica de superfície, incluindo depressões como as dolinas, na condição de forma de relevo. Finalmente, quanto às unidades de conservação, embora as respectivas categorias do SNUC sejam considerados igualmente como subtipologia, no formulário do MTur de 2011 outras áreas designadas de similares, como os zoológicos e jardins bitânicos são acrescidas a esta tipologia, enquanto o modelo aqui proposto detêm-se apenas nas áreas naturais protegidas, por considerar que estas representam amostras originais dos ambientes e ecossistemas naturais objeto de interesse intrínseco do ecoturismo.

\subsection{Proposta para a identificação e descrição dos componentes naturais dos destinos de turismo na natureza com base na composição visual de suas paisagens}

A partir deste modelo de composição visual, e atendendo ao enfoque voltado para os destinos de turismo na natureza no Brasil, apresenta-se a seguir um exemplo aplicado de identificação e correspondente descrição dos componentes naturais da paisagem selecionando, para tanto, três destinos representativos que integram a oferta de agências e operadoras deste segmento.

\section{A) Lençóis Maranhenses (MA)}

Localizado nos municípios de Barreirinhas e Primeira Cruz no litoral sul do Maranhão, este ambiente natural está legalmente protegido como Parque Nacional, uma categoria de unidade de conservação do grupo de proteção integral, que contempla entre os seus objetivos primários o 
turismo. Dessa forma, constitui-se também em um destino nacional de turismo na natureza e ecoturismo. O quadro 5 mostra a composição visual da paisagem neste destino a partir dos componentes físicos e biológicos nela existentes.

Quadro 5 - Composição visual da paisagem no PARNA dos Lençóis Maranhenses

\begin{tabular}{|c|c|}
\hline FATORES DE COMPOSIÇÃO & COMPONENTES BIOFÍSICOS \\
\hline Formas de relevo & $\begin{array}{l}\text { No contexto geomorfológico da Planície Litorânea e } \\
\text { Tabuleiros Costeiros, predomina a forma de relevo planície } \\
\text { arenosa, com montes de areia móvel formando dunas de } \\
\text { variadas dimensões e extensas praias no contato com o mar. } \\
\text { Nos limites ao sul e leste do parque, a planície encontra } \\
\text { algumas falésias, associadas ao relevo elevado dos } \\
\text { tabuleiros. Já na parte oeste, em direção à foz do Rio } \\
\text { Parnaíba, sobressaem os terrenos alagados. }\end{array}$ \\
\hline Elementos da superfície & $\begin{array}{l}\text { Hidrografia } \\
\text { O parque situa-se no contexto das bacias hidrográficas } \\
\text { costeiras nordeste ocidental e os elementos hidrográficos } \\
\text { mais notáveis são as lagoas os rios (Rios Parnaíba e Preguiça) } \\
\text { e alagados. } \\
\text { Vegetação Natural } \\
\text { Pertence ao Bioma da Zona Costeira com formações } \\
\text { pioneiras de influência marinha (restingas), fluviomarinha } \\
\text { (mangues) e fluvial (ervas e capins). } \\
\text { Fauna } \\
\text { Ocorrem aves migratórias como os maçaricos e o trinta-réis- } \\
\text { boreal, répteis com destaque para as tartarugas marinhas e } \\
\text { jacarés e mamíferos como o veado mateiro e a paca além de } \\
\text { peixes, crustáceos e moluscos. }\end{array}$ \\
\hline $\begin{array}{l}\text { Fatores de modificação da paisagem } \\
\text { (Influências climáticas e atmosféricas) }\end{array}$ & $\begin{array}{l}\text { Clima tropical da zona equatorial quente variando de semi- } \\
\text { úmido a semi-árido com estação seca de agosto a dezembro } \\
\text { e estação chuvosa de janeiro a julho. A ação de ventos } \\
\text { constantes associada às ondas e correntes marinhas e } \\
\text { fluviais, molda e movimenta as areias e a vegetação. }\end{array}$ \\
\hline Característica singular da paisagem & $\begin{array}{l}\text { Paisagem Costeira: Paisagem que remete a um ambiente } \\
\text { desértico, porém repleto de formas de vida; Vivacidade de } \\
\text { contrastes entre o alvo das dunas com o azul dos espelhos } \\
\text { d'água e os oásis verdes junto à desembocadura dos rios. }\end{array}$ \\
\hline
\end{tabular}

Fonte: Elaboração própria com base em Parques Nacionais. Brasil (1999); IBAMA (1989); IBGE (1993; 2007)

\section{B) Serra da Capivara (PI)}

Localizada nos municípios de São Raimundo Nonato, Brejo do Piauí, Coronel José Dias e João Costa, na região sudeste do Piauí, este ambienta natural está legalmente protegido como Parque Nacional, uma categoria de unidade de conservação de proteção integral, que contempla entre os seus objetivos primários o turismo e é um destino nacional do turismo na natureza e ecoturismo. O quadro 6 mostra a composição visual da paisagem neste destino a partir dos componentes físicos e biológicos nela existentes. 
Quadro 6 - Composição visual da paisagem no PARNA dos Lençóis Maranhenses

\begin{tabular}{|c|c|}
\hline FATORES DE COMPOSIÇÃO & COMPONENTES BIOFÍSICOS \\
\hline Formas topográficas & $\begin{array}{l}\text { No contexto geomorfológico das Chapadas e Depressões do } \\
\text { Meio Norte, destacam-se as seguintes formas de relevo } \\
\text { serras (da Capivara), vales, planícies, encostas íngremes e } \\
\text { chapada. }\end{array}$ \\
\hline Elementos da superfície & $\begin{array}{l}\text { Hidrografia } \\
\text { O parque situa-se na bacia hidrográfica do Rio Parnaíba e } \\
\text { sob a influência mais localizada dos Rios Piaui e Bom Jesus } \\
\text { da Gurgéia. Destacam-se como elementos hidrográficos os } \\
\text { depósitos de águas da chuva (caldeirões) nas rochas. } \\
\text { Vegetação Natural } \\
\text { Pertence ao Bioma da Caatinga ocorrendo na área do parque } \\
\text { a caatinga alta com destaque para as espécies aroeira e } \\
\text { angico, e estratos mais baixos com vegetação arbustiva e } \\
\text { rasteira onde ocorrem o umbuzeiro e o juazeiro. Porem, } \\
\text { cactos como o facheiro e o mandacaru costumam se } \\
\text { salientar pela sua altura. } \\
\text { Fauna } \\
\text { Aves como a siriema o gavião, araras e papagaios; répteis } \\
\text { como lagartos, a jararaca, a cascavel e a cobra cipó; } \\
\text { mamíferos como a paca, o tatu, a cotia e o preá podem ser } \\
\text { destacados, além do roedor mocó; ainda os felinos gato- } \\
\text { maçambira e o jaguarandi. }\end{array}$ \\
\hline $\begin{array}{l}\text { Fatores de modificação da paisagem } \\
\text { (Influências climáticas e atmosféricas) }\end{array}$ & $\begin{array}{l}\text { Clima tropical da zona equatorial quente com temperaturas } \\
\text { médias superiores a 18o todo o ano, e semi-árido com } 6 \text { a } 8 \\
\text { meses secos e chuvas escassas de novembro a março. Como } \\
\text { em todo o bioma da Caatinga, com a ocorrência de chuvas } \\
\text { produz-se uma fisionomia verdejante à vegetação e uma } \\
\text { maior conspicuidade e mobilidade às formas de vida nele } \\
\text { existentes. }\end{array}$ \\
\hline Característica singular da paisagem & $\begin{array}{l}\text { Paisagem Escultural: Diversidade do relevo com saliências } \\
\text { notáveis como a Pedra furada e os paredões de rochas } \\
\text { sedimentares; Sítios arqueológicos com pinturas rupestres } \\
\text { associados a elementos construídos como sinalização, } \\
\text { passarelas, acessos pavimentados e o Museu do Homem } \\
\text { Americano. }\end{array}$ \\
\hline
\end{tabular}

Fonte: Elaboração própria com base em Parques Nacionais. Soares (1999); IBAMA (1989); IBGE (1993; 2007)

\section{C) Aparados da Serra (RS/SC)}

Localizado na região entre o nordeste do Rio Grande do Sul e o sul de Santa Catarina, este ambienta natural está legalmente protegido como Parque Nacional, uma categoria de unidade de conservação de proteção integral, que contempla entre os seus objetivos primários o turismo. Dessa forma, constitui-se também em um destino nacional de turismo na natureza e ecoturismo. O quadro 7 mostra a composição visual da paisagem neste destino, a partir dos componentes físicos e biológicos nela existentes. 
Quadro 7 - Composição visual da paisagem no PARNA dos Aparados da Serra

\begin{tabular}{|c|c|}
\hline FATORES DE COMPOSIÇÃO & COMPONENTES BIOFÍSICOS \\
\hline Formas topográficas & $\begin{array}{l}\text { No contexto geomorfológico do Planalto das Araucárias e } \\
\text { dos Patamares da Serra Geral, as formas de relevo estão } \\
\text { representadas na porção catarinense do Parque por } \\
\text { montanhas e vales profundos, e na porção riograndense } \\
\text { pelo planalto com coxilhas suaves e recortado por cânions } \\
\text { com paredões íngremes e abismos (Canions do Itaimbezinho } \\
\text { com } 5,8 \mathrm{~km} \text { ), além de afloramentos rochosos. }\end{array}$ \\
\hline Elementos da superfície & $\begin{array}{l}\text { Hidrografia } \\
\text { Alguns riachos na parte alta (Ex. Arroio Faxinalzinho) } \\
\text { despencam na forma de grandes saltos como as cachoeiras } \\
\text { do Tigre e do Véu de Noiva, formando o Rio Perdiz no fundo } \\
\text { dos abismos. } \\
\text { Vegetação Natural } \\
\text { Integra o Bioma Mata Atlântica com ocorrência da floresta } \\
\text { pluvial nas encostas e fundos de cânions, e floresta com } \\
\text { araucária e campos de gramíneas na porção alto do planalto. } \\
\text { Fauna } \\
\text { Mamíferos como o lobo-guará, graxaim-do-campo, veado- } \\
\text { campeiro e puma, aves como gaviões e águias e a gralha } \\
\text { azul, e répteis como lagartos e serpentes. }\end{array}$ \\
\hline $\begin{array}{l}\text { Fatores de modificação da paisagem } \\
\text { (Influências climáticas e atmosféricas) }\end{array}$ & $\begin{array}{l}\text { Clima temperado com temperaturas amenas (média anual } \\
\text { de } 18 \text { o a } 20 \text {-), porém atingindo } 0 \text { a ou menos nos meses de } \\
\text { inverno. Chuvas regulares durante o ano, com maior } \\
\text { intensidade de agosto a outubro. Ocorrência freqüente e } \\
\text { repentina de fortes nevoeiros dificultando a visibilidade. }\end{array}$ \\
\hline Característica singular da paisagem & $\begin{array}{l}\text { Paisagem Acidentada: Notável contraste topográfico na } \\
\text { paisagem com campos extensos sulcados por cânions } \\
\text { profundos e seus penhascos de onde despencam cachoeiras; } \\
\text { Remanescentes da Floresta com Araucária em extinção. }\end{array}$ \\
\hline
\end{tabular}

Fonte: Elaboração própria com base em Parques Nacionais. Brasil (1999); IBAMA (1989); IBGE (1993; 2007)

Além de integrarem a oferta de destinos de turismo na natureza e ecoturismo de agências e operadoras no Brasil, os destinos selecionados permitem um exercício de validação para a aplicação do modelo de caracterização da paisagem aqui proposto, por representarem uma variedade de características diferenciadas relativas aos componentes biofísicos dos seus respectivos ambientes naturais. Tal variedade e riqueza paisagística, está assentada, naturalmente, na formação ecológica dos biomas e ecossistemas que ocorrem nestes destinos e que devido a eles adquirem identidade e diferenciação.

\section{CONSIDERAÇÕES FINAIS}

Desde já, face aos objetivos estabelecidos, cabe esclarecer que não se buscou cotejar os resultados alcançados a partir do presente estudo, diante de um pretenso estado da arte da produção acadêmica sobre o assunto. Certamente esta opção levaria a empreender uma pesquisa bibliográfica sistemática para identificar e incorporar à discussão dos resultados, outros estudos 
congêneres que eventualmente já tenham sido realizados. Efetivamente, no momento, a discussão dos resultados restringiu-se a uma comparação com fontes documentais do Ministério do Turismo, indicando para outra oportunidade um possível estudo voltado para a análise da produção acadêmica sobre o tema.

Não obstante, dado o relativo transito do autor como docente e pesquisador na área de estudo, salvo as referencias bibliográficas clássicas aqui citadas, assim como aquelas de caráter documental oriundas de organismos como a Organização Mundial do Turismo e o Ministério do Turismo, até o momento não é de seu conhecimento prévio a existência de estudos acadêmicos com o enfoque aqui apresentado, ou seja, da proposição de modelos e quadros de referência para o levantamento e descrição dos atrativos do turismo na natureza e ecoturismo e seus componentes naturais nos destinos de turismo na natureza.

Os modelos apresentados pretendem contribuir com o ordenamento e a sistematização de informações sobre os atrativos naturais e suas características e condições relevantes para o aproveitamento pelo ecoturismo, para alcançar um melhor padrão de apresentação e descrição da "matéria prima" das agências e operadoras, para melhor atender às necessidades de qualidade e diferenciação requeridas para este segmento. Um aspecto a destacar durante a discussão dos resultados junto às referências documentais do Ministério do Turismo, foi a não inclusão das tipologias "Fauna / Flora" enquanto recursos biológicos, no atual modelo de formulário do Manual do Pesquisador para os Atrativos Turísticos (Categoria "C").

Quanto ao meio acadêmico, espera-se que os resultados apresentados se constituam em uma contribuição metodológica para o ensino e a pesquisa de iniciação científica sobre o tema em cursos de graduação, ou mesmo, ao nível de pós-graduação para a consolidação do conhecimento específico sobre o tema.

\section{REFERÊNCIAS}

Bagnoli, E. (1989). Contribuição ao levantamento do patrimonio arqueológico, paleontológico, geológico e ecológico do extremo nordeste brasileiro. Natal: PETROBRAS/DEPEX/DEBAR/DINTER/SELAB. (Documento Avulso)

Bombin, E. M. N.; Frutos, M.; Iglesias, E.; Mataix, C.; Torrecilla, I. (1987). El paisaje. Madrid: MOPU. BRASIL. Ministério do Esporte e Turismo/Embratur. (2001). Inventário da Oferta Turística - metodologia. Brasília: EMBRATUR.

(2006) Segmentação do Turismo: marcos conceituais. Brasília: Ministério do Turismo.

(2004). Sistema Nacional de Unidades de Conservação - SNUC. Lei no 9.985 de 18 de junho de 2000; decreto № 4.340, de 22 de agosto de 2002. 5. ed. Aum. Brasília: MMA/SBF.

Ministério do Meio Ambiente. Biodiversidade da zona costeira e marinha. Disponível em:< http://www.mma.gov.br>. Acedido em: outubro de 2010.

(2011). Inventário da oferta turística. Ana C. G. Lima (Coord.) Brasília: Ministério do Turismo. 
Careless, R. (1992). Tourism resoource inventory methodology. In: Annals. World Adventure Travel EcoTourism Congress. Whistler, British Columbia. Canadá.

Cerro, F. L. (1993). Tecnicas de evaluacion del potencial turistico. (Serie Libros sobre Turismo no 2). Madrid: MICYT.

Font, J. N. (1989). Paisaje y turismo. estudios turisticos. Madrid, n. 103, pp. 35-45.

Furio, B. E. (1996). Economia, turismo y medio ambiente. Valencia: Universidad de Valencia.

Guerra, A. T. (1993). Dicionário geológico geomorfológico. 8. ed. Rio de Janeiro: IBGE.

IBAMA-Instituto Brasileiro do Meio Ambiente e dos Recursos Naturais Renováveis. (1989). Unidades de Conservação do Brasil. Brasília: IBAMA.

IBGE. (1993). Recursos naturais e meio ambiente: uma visão do Brasil. (Coord. Sueli S. Caldeiron). Rio de Janeiro: IBGE - Depto. de recursos Naturais e Estudos Ambientais.

(1995). Manual técnico de geomorfologia. Manuais Técnicos em Geociências, n 5. Rio de Janeiro: IBGE - Depto de Recursos Naturais e Estudos Ambientais.

(2007). Atlas geográfico escolar. 4. ed. Rio de Janeiro: IBGE.

Laurie, J.C. (1970). Objetives of landscap evaluation. Landscape Research Group. [S.L.] Conf. II.

Litton, R.B. (1972). Aestetic dimensions of the ladscape. In: Natural environments: studies in theoretical and applied analysis. Balttimore: Johns Hopkins Univ. Press, pp. 262-291

Ministerio de Medio Ambiente - SGT. (2004). Guía para la elaboración de estudios del medio físico: contenido y metodología. Madrid: Ministerio de Medio Ambiente.

Murta, S. M.; Goodey, B. Interpretação do patrimônio para visitantes: um quadro conceitual. In: Murta, S. M.; Albano, C. (2002). Interpretar o Patrimônio: um exercido do Olhar. Belo Horizonte: Editora da UFMG. pp. $13-46$

Najdzion, L. (2002). Oferta turística de passeio de barco: inventário do litoral centro catarinense. Dissertação. Programa de Pós Graduação em Turismo e Hotelaria. UNIVALI. Balneário Camboriú-SC.

OEA-Organização dos Estados Americanos. Metodologia de Inventario turístico. Mimeo. Washington, (S.D)

OMT. Organização Mundial do Turismo. (2001). Introdução ao turismo. Trad. Dolores M. R. Corner. São Paulo: Roca.

Pires, P. S. (2001). Caracterização e análise visual da paisagem rural com enfoque turístico: uma contribuição metodológica. Turismo Visão e Ação. Itajaí, v.4, n.8, pp.83-97.

A Base Ecológica das Paisagens Naturais do Brasil: um aporte metodológico ao inventário da oferta turística. In: Coriolano, L.N.M.T.; Lima, L.C. (org.) (2003). Turismo comunitário e responsabilidade sócio ambiental. Fortaleza: Ed. UECE. 
Entendendo o ecoturismo. In: Trigo, L.G.G. (Ed.). (2005). Análises regionais e globais do turismo brasileiro. São Paulo: Roca.

Interfaces ambientais do turismo. In: TRIGO, L. G. G. (Ed.) (2008). Turismo, como aprender como ensinar. 4. ed. São Paulo: SENAC.

(2011). Marco teórico-metodológico de lós estudios del paisaje: perspectivas de la aplicación em la planificación del turismo. Estudios y Perspectivas em Turismo. Buenos Aires. v. 20, pp. 522-541.

Roa, J.C.; Castillo G., Roberto; Castañeda G., Jerónimo; Sánches O. J. Antonio. (1998). Recursos naturales y turismo. México: Limusa.

Santos, M. (1989). Metamorfoses do espaço habitado. São Paulo: Hucitec.

Silbermann, A. G. (1970) Classificación de los recursos turísticos. Boletim del Instituto de Geografia. México v. 3. pp. 61-65.

Smith, S.L.J. (1992). Geografia recreativa: investigación de potenciales turísticos. México: Ed. Trilhas.

Soares, D. (Coord.) (1999). Parques nacionais: Brasil: guia de turismo ecológico. São Paulo: Empresa das Artes.

Welter, B. M.; Pires, P. S. (2007). Caracterização dos atrativos do turismo na natureza no Brasil. Relatório final da pesquisa PIBIC-CNPq/UNIVALI.

WWF. Biomas e ecorregiões do Brasil. Disponível em http://www.wwf.org.br/informe-se. Acesso em outubro de 2005.

Notas.

Artigo recebido em: 22/11/2012. Artigo aprovado em: 19/11/2013.

\footnotetext{
'Small, J.; Witherich, M. (1986). A new modern dictionary of geography. Ed. Edward Arnold. Londres.

ii Solórzano, M.; Carlos, F. (1962). Los recursos naturales. caracas.

iii Beltrán, E. (1958). Guión para el estúdio de lós recursos naturales renovables em México y su conservación. México, D.F.

O Presente artigo é uma revisão e atualização do trabalho intitulado "TIPOLOGIA DOS ATRATIVOS NATURAIS NOS DESTINOS DE TURISMO NA NATUREZA NO BRASIL E A IDENTIFICAÇÃO DOS SEUS COMPONENTES BIOFÍSICOS ATRAVÉS DO MODELO DE COMPOSIÇÃO VISUAL DA PAISAGEM", apresentado no VIII CONECOTUR-Congresso Nacional de Ecoturismo de 2011. Por sua vez, este trabalho foi gerado a partir de uma pesquisa orientada pelo autor e desenvolvida pela acadêmica de Turismo e Hotelaria Beatriz Moscheta Welter no período 2006-2007, dentro do Programa Institucional de Iniciação Científica - PIBIC-UNIVALI e com apoio financeiro do CNPq.
} 